Revista Triângulo

ISSN 2175-1609

\title{
O CONHECIMENTO PROFISSIONAL DE PEDAGOGOS SOBRE A HABILIDADE DO PENSAMENTO CRÍTICO NO CONTEXTO DA ALFABETIZAÇÃO CIENTÍFICA
}

\author{
THE PROFESSIONAL KNOWLEDGE OF PEDAGOGOS ON THE SKILL OF CRITICAL \\ THINKING IN THE CONTEXT OF SCIENTIFIC LITERACY \\ EL CONOCIMIENTO PROFESIONAL DE PEDAGOGOS SOBRE LA HABILIDAD DEL \\ PENSAMIENTO CRÍTICO EN EL CONTEXTO DE LA LITERACIA CIENTÍFICA
}

\author{
Alessandro Augusto Barros Façanha \\ E-mail: abfacanha@gmail.com \\ Renan Cirne Chianca \\ E-mail: renan04cirne@gmail.com \\ Clara Patricia Felix \\ E-mail: clara.patriciafelix@hotmail.com \\ Universidade Federal do Rio Grande do Norte - UFRN
}

\begin{abstract}
RESUMO
Este estudo apresenta os resultados de uma investigação cujo objetivo foi caracterizar o conhecimento profissional de futuros professores de ciências sobre a habilidade do pensamento crítico e sua relação com a alfabetização científica. Este conhecimento assume relevância no âmbito da profissionalidade docente à medida que o pensamento crítico é uma habilidade cognitiva necessária para ensinar ciências e promover alfabetização científica em sala de aula. Como marco teórico se adotam os referenciais da formação de professores e a profissionalidade docente a partir do contexto da alfabetização científica como conhecimento necessário para o exercício profissional de pedagogos. Nesse sentido foi realizado um estudo de natureza descritiva com estudantes de pedagogia de uma universidade pública de referência da formação de professores e nas pesquisas que envolvem o ensino das ciências. Os resultados auxiliam na compreensão do processo de formação de professores e demonstram, dentre outras constatações, a fragilidade da formação no contexto do ensino de ciências bem como um descompasso entre a profissionalidade e as necessidades atuais para a promoção da alfabetização científica nos anos iniciais da educação básica.
\end{abstract}

PALAVRAS-CHAVE: Formação de professores. Ensino de ciências. Pensamento crítico.

\section{ABSTRACT}

This study presents the results of an investigation whose objective was to characterize the professional knowledge of future science teachers about the skill of critical thinking and its relation with scientific literacy. This knowledge assumes relevance in the scope of their practice professional as critical thinking is a cognitive ability necessary to teach science and promote scientific literacy in the classroom. As a theoretical framework, are adopted the references on teacher education and teacher professionality are adopted from the context of scientific literacy as a necessary knowledge for the professional practice of pedagogues. In this sense, a study of a descriptive nature was carried out with students of pedagogy of a public university of reference of the formation of teachers and in the researches that involve the teaching of the sciences. The result, help in understanding the process of teacher education and show, among other findings, the fragility of training in the context of science education as well as a mismatch between professionalism and current needs for promotion of scientific literacy in the early years of basic education.

KEYWORDS: Teacher training. Science teaching. Critical thinking. 


\section{RESUMEN}

Este estudio presenta los resultados de una investigación cuyo objetivo fue caracterizar el conocimiento profesional de futuros profesores de ciencias sobre la habilidad del pensamiento crítico y su relación con la alfabetización científica. Este conocimiento asume relevancia en el ámbito de la profesionalidad docente a medida que el pensamiento crítico es una habilidad cognitiva necesaria para enseñar ciencias y promover la alfabetización científica en el aula. Como marco teórico se adoptan los referentes de la formación de profesores y la profesionalidad docente a partir del contexto de la alfabetización científica como conocimiento necesario para el ejercicio profesional de pedagogos. En ese sentido se realizó un estudio de naturaleza descriptiva con estudiantes de pedagogía de una universidad pública de referencia de la formación de profesores y en las investigaciones que involucran la enseñanza de las ciencias. Los resultados ayudan en la comprensión del proceso de formación de profesores y demuestra, entre otras constataciones, la fragilidad de la formación en el contexto de la enseñanza de las ciencias así como un descompás entre la profesionalidad y las necesidades actuales promoción de la alfabetización científica en los años iniciales de la educación básica.

PALABRAS-CLAVE: Formación de profesores. Enseñanza de las ciencias. Pensamiento crítico.

\section{INTRODUÇÃO}

As últimas décadas dos anos 90 e o início dos anos 2000 constituem um marco na informação e produção do conhecimento. A sociedade da informação consolida novas tecnologias e modelos hipermodais de comunicação que reconfiguram os espaços educacionais e reafirmam a necessidade de se ter indivíduos cada vez mais críticos diante dos problemas do dia a dia. Tais prerrogativas se refletem no ensino das ciências aonde a necessidade de se formar um cidadão apto a refletir, pensar e tomar decisões se torna um paradigma da atualidade (TENREIRO-VIEIRA; MARQUES VIEIRA, 2013).

Consolida-se a necessidade de um processo de alfabetização científica, aonde, desde os anos iniciais da educação básica, a ênfase na formação das habilidades cognitivas se constitui como um dos pilares do processo de aprendizagem. Por consequência, o desenvolvimento do pensamento crítico passa a ser percebido como um objetivo da alfabetização científica, pois, no âmbito do ensino, consiste em uma habilidade intimamente relacionada à tomada de decisão, resolução de problemas e compreensão da realidade (MOON, 2005).

Nesta seara o olhar se volta para a formação dos pedagogos, pois, como expresso em suas diretrizes curriculares e orientações de atuação, são os profissionais que primeiro inserem os cidadãos no contexto da alfabetização científica através do ensino das ciências a partir dos anos iniciais do ensino fundamental. Conforme expresso nas diretrizes curriculares:

Art. $4^{\circ} \mathrm{O}$ curso de Licenciatura em Pedagogia destina-se à formação de professores para exercer funções de magistério na Educação Infantil e nos 
anos iniciais do Ensino Fundamental, nos cursos de Ensino Médio, na modalidade Normal, de Educação Profissional na área de serviços e apoio escolar e em outras áreas nas quais sejam previstos conhecimentos pedagógicos. Parágrafo único. As atividades docentes também compreendem participação na organização e gestão de sistemas e instituições de ensino, englobando: (...) III - produção e difusão do conhecimento científicotecnológico do campo educacional, em contextos escolares e não escolares.

Art. $5^{\circ} \mathrm{O}$ egresso do curso de Pedagogia deverá estar apto a: (...) VI - ensinar Língua Portuguesa, Matemática, Ciências, História, Geografia, Artes, Educação Física, de forma interdisciplinar e adequada às diferentes fases do desenvolvimento humano. (BRASIL, 2006; p. 2. grifo nosso).

Entretanto, apesar de pertencer às atribuições do pedagogo, a inserção da educação científica no rol da profissionalidade docente ainda é um entrave. Estudos evidenciam uma série de fragilidades na formação dos pedagogos, sobretudo quando se analisam aspectos relacionados ao currículo e as experiências profissionais relativas à epistemologia das ciências, didática das ciências naturais, formação de conceitos científicos e a inserção das habilidades cognitivas na formação inicial, com destaque para o pensamento crítico, que contribuem para um descompasso em relação às necessidades de formação atuais (OVIGLI e BERTUCCI, 2009; OJA e BASTOS, 2013; DUCATTI-SILVA, 2005).

Fragilidades dessa natureza reproduzem lacunas que comprometem a profissionalidade docente e interferem no processo do ensino, da aprendizagem e da formação de sujeitos alfabetizados cientificamente, pois, como declaram os estudos relacionados ao contexto da didática e formação docente, é a profissionalidade que designa as relações dialéticas entre a os conhecimentos, as habilidades e o contexto prático da docência (LÜDKE; BOING, 2004; ROLDÃO 2011; NUÑEZ; RAMALHO, 2008), consequentemente, deficiências na formação dos professores corroboram para práticas pedagógicas descontextualizadas com as necessidades de formação dos estudantes.

No caso específico da educação científica e seu processo de alfabetização, prejuízos de formação coincidem diretamente na profissionalidade docente e comprometem a atuação profissional do pedagogo em suas práticas didático-pedagógicas, sobretudo em relação às habilidades cognitivas relacionadas à formação do pensamento crítico, dentre as quais destacam a leitura crítica, a argumentação nas ciências, a redação científica e o próprio desenvolvimento do pensamento crítico para a interpretação dos fenômenos relacionados à ciência. 
Este estudo investiga as relações entre o processo de formação dos pedagogos e o conhecimento profissional sobre a habilidade do pensamento crítico no contexto da alfabetização científica, a fim de se estabelecerem relações entre a profissionalidade e o ensino das ciências. Com o intuito de relacionar a formação inicial e o conhecimento profissional acerca da habilidade do pensamento crítico se desenvolve a partir das seguintes questões de estudo: qual o conhecimento profissional do futuro pedagogo sobre a habilidade do pensamento crítico? O licenciando de pedagogia relaciona a formação do pensamento crítico como uma necessidade para o ensino das ciências? Qual a percepção dos futuros pedagogos sobre a importância do pensamento crítico no contexto da alfabetização científica?. Como desdobramento se discute o processo de formação em termos da profissionalidade e os fundamentos da habilidade do pensamento crítico à luz do processo de alfabetização científica no ensino das ciências.

\section{REFERENCIAL TEÓRICO}

\subsection{O PENSAMENTO CRÍTICO COMO HABILIDADE COGNITIVA PARA APRENDER E ENSINAR CIÊNCIAS}

As concepções de ensino e aprendizagem são influenciadas pela dinâmica da sociedade, suas demandas sociais e pelo papel que se espera da escola e de seus professores. Observando esse cenário a partir das ideias de Libâneo (2009), percebe-se que a sociedade do século XXI pressiona as instituições de ensino a formarem professores inseridos no contexto das habilidades cognitivas como um pressuposto para formação de cidadãos aptos a lidarem com os conflitos da sociedade, das informações e do desenvolvimento científico.

No campo da alfabetização científica se exige que a escola seja um espaço de discussão das informações à luz da resolução de problemas do cotidiano, da análise crítica das informações e da busca pela interpretação dos fenômenos a partir de critérios de argumentação e credibilidade, que, além de se configurar como uma expectativa insere a habilidade do pensamento crítico na formação de cidadãos engajados no contexto social, político e democrático (FOUREZ, 2016).

Consequentemente, passa a se exigir professores cada vez mais capacitados e articulados com a realidade de uma sociedade em constante dinamismo em relação as informações e ao conhecimento. Inserir o pensamento crítico nesse processo de formação dos 
professores se torna uma tarefa das licenciaturas, pois, em consonância com o que expressa Tittle (2011), pensar criticamente se configura como uma habilidade estruturante do pensamento humano que, não só possibilita uma amplitude da capacidade de aprender, como também subsidia a aquisição de áreas do conhecimento que integram o pensamento e as estratégias de aprendizagem.

No âmbito da educação brasileira se percebe a preocupação com a inserção do pensamento crítico a partir da necessidade de se formar melhor os cidadãos, não só para atuarem no mercado de trabalho, mas para se inserirem socialmente. De acordo com Saviani (2006), essa importância tem origem no contexto educacional no final do século XX e início de século XXI, a partir da crítica ao modelo técnico racionalista que enfatizava a memorização, a recepção e a reprodução dos conceitos. Assim, em consonância com as críticas ao modelo tecnicista, surgem novos paradigmas educacionais para as ciências que orientam para o desenvolvimento conceitual dos conteúdos, adoção de estratégias para resolução de problemas do dia a dia, contextualização dos assuntos e o uso do pensamento crítico e reflexivo como via de desenvolvimento cognitivo (KRASILCHIK, 2008).

Em função de seu alinhamento à lógica e ao desenvolvimento de uma epistemologia do conhecimento, surge a necessidade de se desenvolver o pensamento crítico nas ciências como uma contribuição para a formação de cidadãos inseridos no contexto de uma sociedade dialética, aonde a necessidade de se pensar criticamente evolui a medida que se reformula o discurso educacional (VIEIRA; TENREIRO-VIEIRA; MARTINS, 2011).

Nesse sentido, atualmente o pensamento crítico se configura como uma condição necessária à educação em seu sentido mais amplo, ou seja, para a inserção dos cidadãos em seu cotidiano social, político e para a cidadania, pois, além de promover um reordenamento do pensamento em direção à autonomia e reflexão, caracteriza-se como um referencial para a formação do cidadão no contexto da sociedade contemporânea (BROWN, 1996; VIEIRA; VIEIRA, 2005). Do ponto de vista epistemológico, para além da concepção de uma nova habilidade em educação, consolida-se no plano conceitual, didático e metodológico, pois incorpora na formação do indivíduo, além de atributos do desenvolvimento cognitivo, multidimensões de convívio, reflexão e atuação na sociedade, caracterizando-o assim, como um processo do desenvolvimento humano (VIEIRA; TENREIRO-VIEIRA; MARTINS, 2011). 
A adoção do pensamento crítico como uma premissa da educação científica, portanto, passa a se configurar como um pressuposto para aprender e ensinar ciências, pois, para além de uma educação científica que supõe apropriar-se da linguagem da ciência e de novas formas de ver, pensar e falar sobre os fatos e fenômenos da natureza, pensar criticamente possibilita novas e diferentes formas de ver, pensar e se expressar a partir de um ponto de vista científico (SANMARTÍ, 2007).

Tomando os normativos educacionais brasileiros em sua atualidade se percebe que essas proposições deixam de ser uma mera redundância do discurso e passam a se configurar como um paradigma. Exemplo disso é a referência ao pensamento crítico como uma competência prevista na base nacional curricular comum, aonde se verifica a concepção do pensamento crítico como um conhecimento necessário para ensinar e aprender ciências que se expressa a partir da ideia de se desenvolver a análise crítica e o pensamento reflexivo para a tomada de decisão, a interpretação dos fenômenos e compreensão do cotidiano como resultado do letramento científico.

Como competências do ensino das ciências: exercitar a curiosidade intelectual e recorrer à abordagem própria das ciências, incluindo a investigação, a reflexão, a análise crítica. (...) ao longo do Ensino Fundamental, a área de Ciências da Natureza tem um compromisso com o desenvolvimento do letramento científico ${ }^{1}$, que envolve a capacidade de compreender e interpretar o mundo (natural, social e tecnológico), mas também de transformá-lo com base nos aportes teóricos e processuais das ciências. (BRASIL, 2015, p.11, 321, grifo nosso).

Desse modo, em se tratando dos pedagogos, é possível estabelecer, uma vez que são os profissionais que primeiro executam o ensino das ciências na educação básica, a necessidade do conhecimento profissional do pensamento crítico como uma habilidade referente não só ao ensino a aprendizagem, mas, principalmente, como uma via para o desenvolvimento da alfabetização científica em sua profissionalidade.

\footnotetext{
${ }^{1}$ O Termo "literacy", do anglo-saxão, não apresenta uma tradução similar para o português, desta forma, em consonância com o relatório do INEP/2006, apresenta-se de modo a designar "alfabetização" científica, uma vez que, aborda o conceito de competência científica, com as dimensões das habilidades, atitudes e competências. No entanto, apesar de contextos distintos, em alguns estudos, o termo é tratado conceitualmente como "letramento científico", mesmo não guardando entre si uma relação linguística e semântica de sinonímia. (TEIXEIRA, 2013)
} 


\subsection{O PENSAMENTO CRÍTICO NO CONTEXTO DA ALFABETIZAÇÃo CIENTÍFICA E DA PROFISSIONALIDADE DOCENTE}

A designação léxica em torno do termo não é consensual, assim, na literatura ora é transcrito como alfabetização, ora como letramento científico, no entanto, para além dessa divergência semântica, há consenso em relação ao seu aspecto conceitual, de modo que a alfabetização científica se configura como a capacidade de empregar o conhecimento científico para explicar fenômenos cientificos, tirar conclusões baseadas em evidências, ter consciência das aplicações científicas no cotidiano e atuar na sociedade de forma crítica (ICSU, 2011, p.10).

Assim, a incorporação do pensamento crítico no contexto da alfabetização científica ocorre em função da compreensão da ciência como um conhecimento aplicado ao cotidiano e presente nas tomadas de decisão de forma crítica no sentido de sua validade, da tomada de decisão e resolução de problemas de maneira que se amplifique a participação social dos indivíduos (TENREIRO-VIEIRA; VIEIRA, 2013).

Tal compreensão, ao invés de perceber o significado de se pensar criticamente como uma ação isolada em si mesmo, passa a compreender a importância de se desenvolver o pensamento crítico a partir de sua associação ao processo de uma educação científica no contexto da sociedade tecnológica moderna, aonde pensar de forma crítica é uma premissa do desenvolvimento do pensamento lógico e da validação das ideias como forma de se aplicar o conhecimento científico (TENREIRO-VIEIRA, 2004).

Nesse aspecto, educar os sujeitos para pensarem criticamente o mundo significa permitilos ao convívio racional com as questões e problemas cotidianos das ciências, ensejar a participação social ativa, aonde o indivíduo atua na e sobre a sociedade, interpretando seus fenômenos, conferindo-lhes juízo de valor e adotando estratégias para tomar as melhores decisões diante da realidade. Essas prerrogativas já são substanciadas em muitos estudos que correlacionam o pensamento crítico e a educação científica, como refere o próprio Conselho Internacional de Ciências (ICSU, 2011), pensar de forma crítica, proporciona aos cidadãos as ferramentas necessárias para o debate racional e a tomada de decisão esclarecida sobre questões socialmente relevantes que envolvem a ciência e a tecnologia.

A isso é o que se denomina de um processo de alfabetização científica plena, o qual se observa como propósito da educação científica nas matrizes de referência avaliativas, a 
exemplo do que ocorre no Programa Internacional de Avaliação de Estudantes (PISA), no Sistema de Avaliação da Educação Básica (SAEB) e no Exame Nacional do Ensino Médio (ENEM), aonde se percebe que o pensamento crítico é um objeto previsto nas competências científicas que determinam o conhecimento do conteúdo, dos procedimentos e da compreensão lógica associada aos conceitos científicos e seu processo de aprendizagem.

Nesse sentido se percebe a relação entre o pensamento crítico e a educação científica como uma proposta a ser alcançada visto que as matrizes de referências dos exames de proficiência são balizadores importantes dos conteúdos curriculares previstos e esperados para uma educação científica. No entanto, a justificativa para a inserção do pensamento crítico ao ensino das Ciências não reside de um alinhamento aos exames de avaliação, ao contrário, pensar criticamente corresponde a um pressuposto orientado para educação científica, o qual é materializado na perspectiva dos exames, porém sua incorporação supera o mero espectro da avaliação ou ranqueamento, visto que passa a ser uma prerrogativa do novo modelo que se espera da escola e de seus professores (LIBÂNEO, 2014).

Portanto, a importância do pensar criticamente supera uma simples mensuração de habilidades e competências esperadas para os egressos da educação básica e passa a se configurar como um conceito chave da alfabetização, pois pessoas cientificamente alfabetizadas estão mais bem habilitadas a compreender e a participar das discussões sociais e suas desigualdades, pois uma das finalidades da educação em ciências é integrar os sujeitos de forma a perceberem a importância de uma educação científica inclusiva em todos os sentidos (VIEIRA; VIEIRA, 2005).

Nessa perspectiva se salienta que a ciência deve deliberar sobre questões sociais onde os futuros cidadãos possam se educados para serem consumidores críticos do conhecimento científico, pois a literacia científica só faz sentido se fizer parte de um conhecimento que subsidie o pensamento crítico.

A educação em ciências numa perspectiva de literacia científica poderá ajudar os indivíduos a compreender os problemas do mundo e a contribuírem para a construção de propostas de resolução e cursos de ação que permitam minorá-los. Poderá, igualmente, estimular as pessoas a usar informação e formas de pensar, incluindo o pensar de forma crítica, para a tomada de decisão esclarecida e racional, para a resolução de problemas e para a participação ativa e responsável numa sociedade democrática (TENREIROVIEIRA, 2014, p. 32). 
Entretanto, para que não se configure apenas como retórica ou um mero acervo de orientações curriculares, o pensamento crítico precisa fazer parte da profissionalidade docente, sobretudo no campo da didática das ciências como conhecimento profissional de pedagogos, pois, em termos escolares são os primeiros a promoverem a alfabetização científica aos estudantes.

Inúmeras pesquisas já defendem que a habilidade cognitiva do pensamento crítico esteja no rol dos conhecimentos necessários à formação de professores, uma vez que, em termos de profissionalidade, é necessário desenvolver conhecimentos, habilidades, atitudes e competências para a ampla profissionalização da docência (RAMALHO; NÚÑEZ; GAUTHIER, 2004).

A inserção de habilidades cognitivas, dentre as quais o pensamento crítico, no rol da profissionalidade docente, corrobora, não somente para a profissionalização da docência mas, sobretudo, para uma ruptura com o modelo de formação para o ensino das ciências, pois não basta o olhar da sociedade sobre as diretrizes da educação e os propósitos da escola na formação dos cidadãos se esse mesmo olhar não mirar uma reformulação das práticas educativas, que não podem ficar apenas sob a responsabilidade de projetos pedagógicos e direcionamentos acadêmicos.

Ao contrário, a profissionalização da docência e uma reformulação da formação dos professores precisam se uma preocupação da sociedade como um todo, pois, a medida que se associarem as expectativas de inserção do cidadão crítico na sociedade com novas propostas para a formação docente, que, no caso específico da alfabetização científica, integre o preparo pedagógico à uma nova profissionalidade se estará superando a dicotomia entre o conteúdo e as habilidades didáticas e se favorecendo um trabalho docente dialético que une as relações entre o conhecimento científico e como ensinar esse conhecimento (MAIZTEGUI et al, 2000).

Nesse aspecto este estudo, além de objetivar compreender o conhecimento profissional sobre o pensamento crítico por parte de pedagogos em formação, traz à tona a necessidade de se fazer uma intersecção dessa habilidade em seu campo cognitivo (SOLBES E MERCHÁN, 2013), e ao mesmo tempo, reiterando a necessidade de sua inserção ao espectro de formação docente a fim de conciliar a didática das ciências naturais como um conhecimento profissional no âmbito da profissionalidade de pedagogos, a fim de propiciar, através da produção de 
conhecimento acadêmico, um espaço para se pensar o processo de alfabetização científica como proposta do ensino das ciências que integra saberes profissionais, hábitos, reflexões, rotinas e múltiplas teorias de natureza didática e cognitiva (PORLÁN et al, 1998).

\section{DELINEAMENTO DO ESTUDO: UM APORTE METODOLÓGICO}

O estudo retrata uma investigação realizada com 18 licenciandos do curso de Pedagogia da Universidade Federal do Rio Grande do Norte campus de Caicó/RN, na disciplina de metodologia do ensino das ciências, dos quais $11 \%$ eram homens, $89 \%$ mulheres e cuja média de idade era de 23,55 anos. Em relação à origem escolar dos participantes, 78\% eram oriundos da escola pública enquanto $22 \%$ ingressaram na universidade advindos de escolas da rede privada de ensino.

Utilizou como estratégia de investigação a pesquisa descritiva, pois no campo da pesquisa pedagógica permite observar, registrar e interpretar um fenômeno em seu espaço temporal presente e se traçar conjecturas e relações com variáveis que possibilite um diagnóstico (MEZQUITA; RODRÍGUEZ, 2009).

Dessa forma, como o objetivo se delimita investigar as relações entre o conhecimento profissional de futuros pedagogos acerca da habilidade cognitiva do pensamento crítico, tal desenho de pesquisa se alinha aos questionamentos da pesquisa sobre: qual o conhecimento profissional do futuro pedagogo sobre a habilidade do pensamento crítico? O licenciando de pedagogia relaciona a formação do pensamento crítico como uma necessidade para o ensino das ciências? Qual a percepção dos futuros pedagogos sobre a importância do pensamento crítico no contexto da alfabetização científica?

Para a coleta dos dados optou-se pelo questionário de conteúdos define uma técnica de investigação composta por um número mais ou menos elevado de questões apresentadas às pessoas, tendo por objetivo o conhecimento de opiniões, crenças, sentimentos, interesses, expectativas, situações vivenciadas (CEREZAL; FIALHO, 2004). A fim de validação questionário foi elaborado por pesquisadores da área, os quais seguiram um padrão de validade de pesquisas similares, além de garantir, segundo os preceitos éticos de pesquisa dessa natureza, anonimato e sigilo dos participantes. A aplicação se deu de forma coletiva onde foram esclarecidas dúvidas, propósitos e objetivos. 
Para a análise dos dados seguiu-se a técnica da análise do conteúdo, a qual se aplica ao estudo da história, das relações, das representações, das crenças, das percepções e das opiniões, produto das interpretações que os seres humanos fazem de como vivem, constroem seus artefatos e a si mesmos, sentem e pensam (BARDIN, 1977).

Em relação às análises da coleta definiram-se categorias de acordo com as respostas analisadas e em consonância com os objetivos previamente propostos, agrupadas em tabelas que explicitam os resultados em função de: aspecto conceitual sobre pensamento crítico, caracterização do pensamento crítico, importância no ensino das ciências e pensamento crítico no contexto da formação inicial de pedagogos.

\section{ANÁLISE DOS DADOS E RESULTADOS}

Para responder as questões iniciais que deram origem ao objeto do estudo se dividiu em categorias que foram tabuladas e apresentadas de acordo com os objetivos principais da investigação. Ressalta-se a importância dessas análises no âmbito da didática das ciências, pois, na percepção das atuais pesquisas é nítida a constatação de que a formação dos professores de ciências, quer nas licenciaturas específicas, quer na concepção dos professores egressos da pedagogia, carecem de aspectos de formação em relação à habilidades dessa natureza (SOLBES E MERCHÁN, 2013).

Nesse sentido as discussões também demonstram importância em relação à profissionalidade dos futuros pedagogos e essa inserção no contexto do ensino das ciências com finalidade de promoção da alfabetização científica. As respostas foram agrupadas em função do conteúdo expresso no discurso dos estudantes e para fins didáticos de entendimento e agrupamento seguem elencados na sequência.

\subsection{Acerca do conhecimento conceitual de pensamento crítico}

Essa categoria se mostra relevante para a pesquisa, pois em consonância com as ideias de Carvalho e Gil-Pérez (2003), uma premissa básica para o ensino das ciências consiste no conhecimento tácito do que será ensinado, logo, para ensinar um conteúdo/habilidade é preciso conhecer o que se trata. Dessa forma, como defendido ao longo deste estudo, para se planejar um ensino de ciências pautado na formação do pensamento crítico é imprescindível 
que se conheça conceitualmente do que se trata. Nesse sentido, as respostas à pergunta conceitual sobre esta habilidade obtiveram o registro expresso pelo gráfico abaixo:

Gráfico 1: Distribuição das respostas sobre o conceito de pensamento crítico.

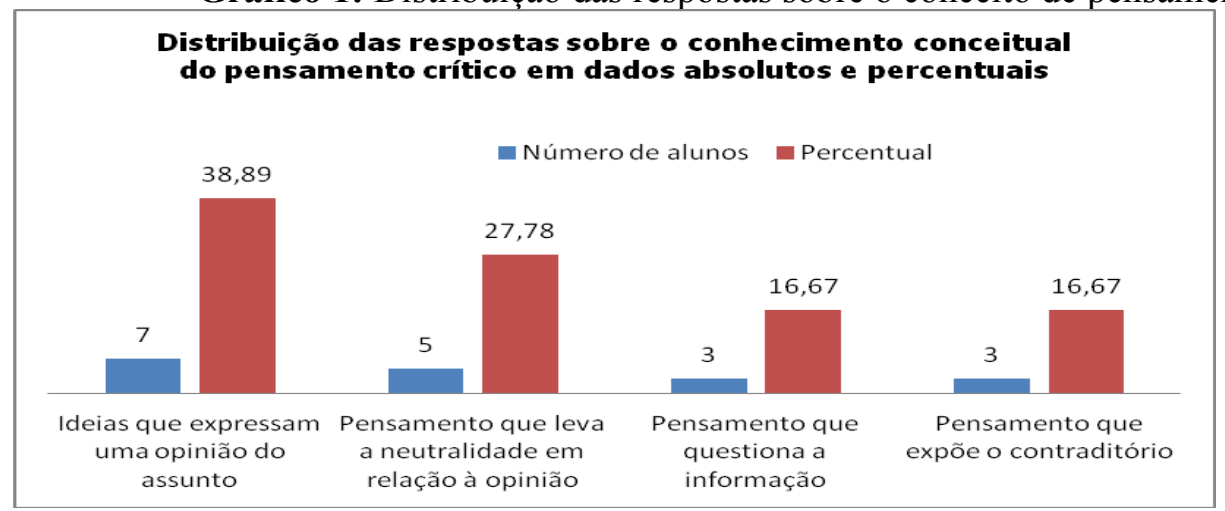

(Fonte: elaborado pelo autor) 
Como estratégia de análise as respostas dos estudantes foram comparadas com os conceitos válidos sobre o que é o pensamento crítico, a partir das definições expressas por Tenreiro-Vieira e Vieira (2014), Moon (2005), Paul e Elder (2009), além das definições referendadas pelas matrizes avaliativas dos exames de proficiência. Neste aspecto se observou que, apesar de haver menção sobre categorias que fazem parte do pensamento crítico, como a ideia do contraditório ou do questionamento da informação presentes em 33,34\% das respostas, há uma nítida distorção conceitual na maioria dos alunos que participaram do estudo, pois $66,67 \%$ dos estudantes trazem ideias equivocadas sobre o conceito trazendo à tona as categorias da opinião e da neutralidade como caracterizações do pensamento crítico.

Merece destaque essa defesa de neutralidade como uma característica do pensamento crítico, pois esta ideia fere em essência a noção da crítica e demonstra um enraizamento do senso comum sobre o fato, pois conforme demonstram as evidências atuais sobre o pensamento crítico das ciências, sobretudo em função do letramento científico, como expressam Tenreiro-vieira e Vieira (2011, 2013), Vieira; Tenreiro-vieira e Martins (2011), a neutralidade em hipótese alguma pode estar presente na concepção do pensamento crítico uma vez que as ciências e a interpretação de seus fenômenos jamais serão neutros ou conferirão neutralidade em suas interpretações.

Portanto, à luz da profisssionalidade e no âmbito das evidências que defendem a inserção tanto do pensamento crítico como de demais habilidades que propiciem a compreensão das competências científicas no ensino das ciências, como defendem Nuñez e Ramalho (2015), constatam-se nas respostas lacunas de natureza epistemológica na construção de conceitos o que é preocupante no contexto da alfabetização científica inicial, pois aproxima o pensamento do entendimento comum ao invés de propiciar uma visão crítica e argumentativa.

Também se destaca uma análise conceitual desvinculada de uma reflexão analítica, dada a ênfase das respostas em relação à opiniões e confronto de ideias como cerne do conceito ao invés de uma percepção em função da dialética, assim, é possível configurar uma desvinculação com a natureza processual da construção do pensamento crítico.

\subsection{Sobre a necessidade do pensamento crítico no contexto da alfabetização científica.}

No contexto dos objetivos essa categoria avaliza o objetivo de correlacionar a compreensão da habilidade do pensamento crítico com a profissionalidade do futuro pedagogo, pois, em conformidade com as ideias defendidas por ramalho, Gauthier e Nuñez 
(2003), Nuñez e Ramalho (2008), as habilidades cognitivas são um escopo da profissionalidade que possibilitam a profissionalização docente. Além disso, como demonstram as evidências de grupos consolidados na pesquisa sobre o ensino de ciências, como o caso expresso por Jorba, Gómez e Prat (2000), que defendem a inserção de habilidades linguísticas e cognitivas como prerrogativa para a alfabetização científica, evidenciar esta categoria amplia a interpretação do objeto investigado.

Dessa maneira, para os dados referentes à importância dada ao pensamento crítico no ensino as respostas foram agrupadas de acordo com o gráfico abaixo.

Gráfico 2: Distribuição das respostas sobre a necessidade do pensamento crítico no contexto da alfabetização científica.

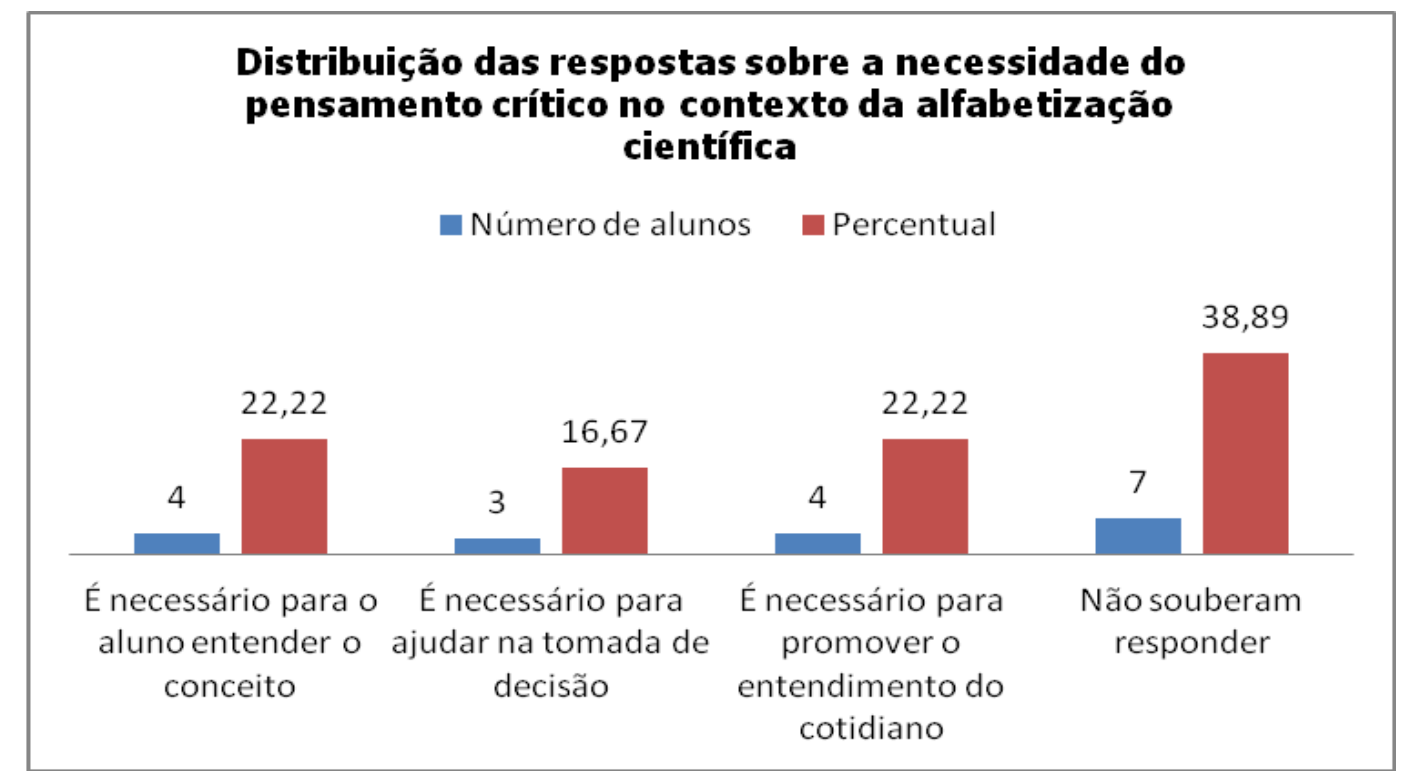

(Fonte: elaborado pelo autor)

Observando os resultados em termo das categorias isoladas até que torna razoável compreender que há convergências entre as respostas e a definição de alfabetização científica adotada pela comunidade científica e pelas matrizes de referência dos exames de avaliação de proficiência, pois as respostas de $61,11 \%$ dos estudantes trazem um alinhamento com as características necessárias, como a compreensão conceitual, o entendimento dos fenômenos no cotidiano e a tomada de decisão, próprios das definições presentes no âmbito das atuais diretrizes (OCDE, 2000; ISCU, 2011; UNESCO, 2003); no entanto, é preciso considerar que estas respostas mencionam uma fragmentação do conceito se forem percebidas como agrupamentos, ou seja, é como se esse quantitativo de alunos percebessem as habilidades cognitivas da compreensão conceitual, interpretação dos fenômenos e tomada de decisões 
separadas entre si e como fins em si mesmo, assim, como percebe Gatti (2009), por exemplo, há um descompasso na formação quando se avalia o conhecimento conceitual e procedimental demonstrando a fragilidade da formação dualista entre teoria/prática e conhecimento/atitude, que no caso do ensino das ciências e a promoção da alfabetização científica é preocupante, pois a medida que o pensamento dessas habilidades está fragmentado a própria tomada de decisões e resolução de problemas fica prejudicada, pois o fenômeno não está separado de sua resolução.

Outro dado que merece atenção corresponde ao amplo percentual de alunos que não souberam responder à questão, 38,89\%, contrariando as perspectivas das atuais necessidades da educação científica, uma vez que entre as habilidades necessárias se incluem o conhecimento do que deve ser ensinado e as aplicações desses conteúdos no âmbito da formação cidadã contemporânea (CARVALHO e GIL-PEREZ, 2006; CACHAPUZ, 2005). Assim, considerando que os pedagogos são os profissionais responsáveis pela iniciação dos estudantes no processo de alfabetização científica essa realidade põe um alerta sobre a formação inicial desses profissionais, que apesar de não significar um percurso final para a profissionalização, incide em uma etapa de extrema importância, sobretudo por ser a base do conhecimento profissional adquirido.

Nesse sentido, em condições ideais era estimando que o futuro professor das ciências tivesse uma compreensão mais sistêmica do processo e da importância do pensamento crítico no desenvolvimento dos estudantes, pois esse descompasso com as necessidades formativas pode influenciar negativamente do planejamento didático e levar as aulas de ciências para uma ação desmotivante, descontextualizada e meramente reprodutora.

\section{CONSIDERAÇÕES FINAIS}

Apesar de não serem possíveis conclusões e extrapolações que levem à generalizações dos dados e dos resultados, dado o recorte e a delimitação de estudos dessa natureza, é possível traçar generalidades e tomar como referência a ser explorada e confrontada com as evidências da vasta literatura específica acerca da formação docente, de sua profissionalização e dos desdobramentos específicos do ensino e da problemática que envolve a sala de aula.

Tomando as análises no âmbito geral da educação científica apesar dos avanços demonstrados nos índices e pesquisas da área, ainda se percebe um distanciamento entre a 
formação inicial de pedagogos e a educação científica, sobretudo quando se mensuram questões específicas do conhecimento profissional, como habilidades cognitivas, competências formativas e profissionalidade docente.

Delimitando o olhar em função do pensamento crítico é possível se evidenciar lacunas epistemológicas em relação à natureza das ciências, às habilidades a serem promovidas no contexto da educação científica, dos propósitos se alfabetizar cientificamente desde os primeiros anos escolares e principalmente sobre o papel docente neste processo quando se refere ao pedagogo.

Tais evidências, à luz do conhecimento profissional e da profissionalização docente, como referência de análises, desvelam panoramas de formação ainda descontextualizados dos atuais pressupostos e das necessidades para o ensino das ciências, uma vez que, como corroboram Ramalho, Núñez e Gauthier (2004), sem essas aproximações da formação profissional não é possível se avançar no âmbito de educação contemporânea.

Além disso, na perspectiva do objeto principal da análise - o pensamento críticoobserva-se ainda um hiato conceitual na formação dos futuros pedagogos, pois se evidencia um entendimento desta habilidade mais voltada para o plano didático-metodológico do que conceitual em si. Não obstante, essas divergências acarretam problemas de sequências didáticas e da elaboração de atividades docentes futuras.

Nesse contexto, portanto, conclui-se por esta pesquisa que assim como se evidencia na vasta literatura sobre formação profissional e habilidades formativas, há uma necessidade premente de se convergir a formação em pedagogia para o contexto das habilidades cognitivas, dentre as quais, o pensamento crítico, sob o risco de se perenizar uma formação fragmentada e com uma visão linear de ciências. 


\section{REFERENCIAS}

BRASIL. 2015. Base Nacional Comum Curricular (BNCC). Consulta Pública. Brasília, MEC/CONSED/UNDIME. Disponível

em: http://basenacionalcomum.mec.gov.br/documento/BNCC-APRESENTACAO.pdf. Acesso em: Jul/2018. maio 2006 .

, Resolução n.1, 15.5.2006. Diário Oficial da União, n.92, seção 1, p.11- 12, 16

BARDIN, Laurence. Análise de conteúdo. Lisboa: Edições, v. 70, 1977.

BROWN, Ken. Education, culture and critical thinking. 1996. Tese de Doutorado. University of Aberdeen.

CARVALHO, Anna M. Pessoa de; Gil-Pérez, Daniel. Formação de professores de ciências, v. 6, 2003.

CEREZAL, J.; FIALLO, J. Como Investigar en Pedagogía. Editorial Pueblo y Educación. La Habana, Cuba, 2004.

COTTRELL, Stella. Critical thinking skills: Developing effective analysis and argument. Palgrave Macmillan, 2011.

DARLING-HAMMOND, Linda; MUÑOZ, Juan Manuel Escudero. El derecho de aprender: Crear buenas escuelas para todos. Ariel, 2001.

DUARTE, Newton. Sociedade do conhecimento ou sociedade das ilusões. Campinas: autores associados, 2003.

DUCATTI-SILVA, K. C. A formação no curso de Pedagogia para o ensino de ciências nas séries iniciais. Dissertação de Mestrado, Programa de Pós-Graduação em Educação, Faculdade de Filosofia e Ciências, Universidade Estadual Paulista "Júlio de Mesquita Filho", Marília, SP, 2005.

FOUREZ, Gérard. Crise no ensino de ciências?.Investigações em ensino de ciências, v. 8, n. 2, p. 109-123, 2016.

GATTI, B.A.; BARRETO, E.S.S. Professores: aspectos de sua profissionalização, formação e valorização social. Brasília, DF: UNESCO, 2009. (Relatório de pesquisa).

GATTI, Bernardete A.; NUNES, Marina Nuniz Rosa. Formação de professores para o ensino fundamental: estudo de curículos das licenciaturas em pedagogia, lingua portuguesa, matemática e ciências biológicas. Textos FCC, v. 29, p. 155, 2013.

International Council for Science [ICSU] (2011). Report of the ICSU ad-hoc review panel on science. Paris: InternationalCouncil for Science. [Disponível em: www.icsu.org]. (Acessado em Julho de 2018).

KRASILCHIK, Myriam. Caminhos do ensino de ciências no Brasil. Em Aberto, v. 11, n. 55, 2008.

LIBÂNEO, José Carlos. Adeus professor, adeus professora?. Cortez Editora, 2014. 
. A didática e as exigências do processo de escolarização: formação cultural e científica e demandas das práticas socioculturais. Anais do III Encontro Nacional de Didática e Prática de Ensino, Anápolis, 2009.

LÜDKE, Menga; BOING, Luiz Alberto. Caminhos da profissão e da profissionalidade docentes. Educação \& Sociedade, v. 25, n. 89, 2004.

MAIZTEGUI, Alberto et al. La formación de los profesores de ciencias en Iberoamérica. Revista Iberoamericana de Educación, n. 24, p. 163-187, 2000.

MEZQUITA, Julio Cerezal; RODRÍGUEZ, Jorge Fiallo. Cómo investigar en Pedagogía. Editorial Pueblo y Educación, 2009.

MOON, Jennifer A. We Seek it Here-a new perspective on the elusive activity of critical thinking: a theoretical and practical approach. 2005.

NÚÑEZ, Isauro Beltrán; RAMALHO, Betania Leite. A profissionalização da docência: um olhar a partir da representação de professoras do ensino fundamental. Revista Iberoamericana de educación, v. 9, n. 46, p. 1-15, 2008.

Conhecimento profissional para ensinar a explicar processos e fenômenos nas aulas de Química. Revista Educação em Questão, v. 52, n. 38, p. 243-268, 2015.

OJA, Aline Juliana; BASTOS, Fernando. Ensino de ciências no início da educação fundamental: algumas implicações para uma educação científica de qualidade. IX Encontro Nacional de Pesquisa em Educação em Ciências, 2013.

OSBORNE, Jonathan; DILLON, Justin. Science education in Europe: Critical reflections. London: The Nuffield Foundation, 2008.

OVIGLI, Daniel Fernando Bovolenta; BERTUCCI, Monike Cristina Silva. A formação para o ensino de ciências naturais nos currículos de pedagogia das instituições públicas de ensino superior paulistas. Ciências \& Cognição, v. 14, n. 2, p. 194-209, 2009.

PAUL, Richard; ELDER, Linda. Critical thinking. The Foundation for Critical Thinking, 2008.

PORLÁN, Rafael et al. El conocimiento de los profesores: una propuesta formativa en el área de ciencias. 1998.

RAMALHO, B. L.; NUÑEZ, I. B.; GAUTHIER, C. Um quadro paradigmático para a mudança: a propósito da formação e da profissionalização docente inicial. Formar o professor, profissionalizar o ensino: perspectivas e desafios, v. 2, p. 17-96, 2004.

ROLDÃO, Maria do Céu. Profissionalidade docente: o tempo e o modo de uma transformação. Formação de educadores: dilemas contemporâneos. São Paulo: Unesp, p. 15-24, 2011.

SANMARTÍ, Neús Puig. Hablar, ler y escribir para aprender ciência. In: ALEIXANDRE, Maria Del Pilar Jimenez (Org.). La competência em comunicación linguística em las áreas del currículo. Madrid: Ministerio de Educación y Cultura, 2007.

SAVIANI, Dermeval. O legado educacional do século XIX. Forward Movement, 2006. 
SOLBES, Jordi; MERCHÁN, Nidia Yaneth Torres. ¿ Cuáles son las concepciones de los docentes de ciencias en formación y en ejercicio sobre el pensamiento crítico?. Tecné, episteme y didaxis: revista de la Facultad de Ciencia y Tecnología, n. 33, p. 61-85, 2013.

TEIXEIRA, Francimar Martins. Alfabetização científica: questões para reflexão. Bauru, Ciênc. Educ, v. 19, n. 4, p. 795-809, 2013.

TENREIRO-VIEIRA, Celina. Formação em pensamento crítico de professores de ciências: impacte nas práticas de sala de aula e no nível de pensamento crítico dos alunos. REEC: Revista electrónica de enseñanza de las ciencias, v. 3, n. 3, p. 1, 2004.

Perspectivas futuras de investigação Potenciais convergências com as literacias científicas e matemática. Pensamento crítico na educação: Perspectivas atuais no panorama internacional, p. 29-39, 2014.

TENREIRO-VIEIRA, Celina; MARQUES VIEIRA, R. U. I. Literacia e pensamento crítico: um referencial para a educação em ciências e em matemática. Revista Brasileira de Educação, v. 18, n. 52, 2013.

TENREIRO-VIEIRA, Celina; VIEIRA, Rui Marques. Educação em ciências e em matemática numa perspectiva de literacia: desenvolvimento de materiais didáticos com orientação CTS/pensamento crítico (PC). CTS e educação científica: desafios, tendências e resultados de pesquisas. Brasília: Editora Universidade de Brasília, p. 417-437, 2011.

TITTLE, Peg. Critical thinking: An appeal to reason. Routledge, 2011.

UNESCO. A ciência para o século XXI: uma nova visão e uma base de ação. Brasília: UNESCO, 2003.

VIEIRA, Rui Marques; VIEIRA, Celina Tenreiro. Estratégias de ensino-aprendizagem: o questionamento promotor do pensamento crítico. 2005.

VIEIRA, Rui Marques; TENREIRO-VIEIRA, Celina; MARTINS, Isabel P. Critical Thinking: Conceptual Clarification and Its Importance in Science Education. Science Education International, v. 22, n. 1, p. 43-54, 2011. 